\title{
Mn-DOPPED ZnS QUANTUM DOTS AS SENSITIVE SENSOR FOR DETERMINATION OF CIPROFLOXACIN IN PHARMACEUTICAL AND BIOLOGICAL SAMPLES
}

\author{
MIAN MUHAMMAD ${ }^{{ }^{*}}$, BEHISHT ARA ${ }^{2}$, FAIZ ALI $^{1}$, IZAZ AHMAD $^{1}$ AND HAFEEZ ULLAH ${ }^{1}$ \\ ${ }^{l}$ Department of Chemistry, University of Malakand, Khyber Pakhtunkhwa, Pakistan. \\ ${ }^{2}$ Institute of Chemical Sciences, University of Peshawar, Khyber Pakhtunkhwa, Pakistan.
}

\begin{abstract}
A simple and fast spectrofluorimetric method for determination of ciprofloxacin based on its quenching effect on the fluorescence intensity of colloidal water soluble TGA caped, Mn doped ZnS quantum dots (QDs) has been described. The QDs having characteristic fluorescence spectra with maximum excitation at $315 \mathrm{~nm}$ followed by an emission peak at $632 \mathrm{~nm}$ were characterized using Energy Dispersive X-Ray and X-ray Diffraction techniques. The effect of various parameters such as concentration of QDs, time, $\mathrm{pH}$, common excipients and metal ions on the quenching phenomenon was investigated. Fluorescence quenching was found to be maximum with $10 \mu \mathrm{g} \mathrm{mL}^{-1}$ of QDs at $\mathrm{pH} 8$ and fluorescence intensity was observed to be constant upto $45 \mathrm{~min}$. The Stern-Volmer calibration plot of $\mathrm{F}^{0} / \mathrm{F}$ as a function of ciprofloxacin concentration was found to be linear in the range of $0.5-10 \mu \mathrm{g} \mathrm{mL} \mathrm{m}^{-1}$ with $\mathrm{r}^{2}=0.993$. Under optimal experimental conditions, the method was found to be interference free. The percent relative standard deviation of the proposed method, calculated against method blank, was found to be $1.10 \%$. The limit of detection (LOD) and the limit of quantitation (LOQ) for ciprofloxacin (signal to noise ratio 3:1 for LOD and 10:1 for LOQ) were calculated to be 0.15 and $0.50 \mu \mathrm{g} \mathrm{mL}^{-1}$ respectively. Average percent recoveries $( \pm \mathrm{SD})$ obtained for spiked commercial formulations; ciprol and ciproquine, and serum and urine samples were found to be in the range of $92.2 \pm 1.8 \%$ to $99.5 \pm 1.5 \%, 90.5 \pm 1.2 \%$ to $96.7 \pm 1.4 \%$ and $94.0 \pm 1.2 \%$ to $98.5 \pm 1.4 \%$ respectively. The data evidently proves the potential of the proposed sensor QDs in biological analysis.
\end{abstract}

Keywords: Spectrofluorimetric; Ciprofloxacin; Quenching; Quantum dots; Fluorescence intensity.

\section{INTRODUCTION}

Ciprofloxacin (Cf) is a synthetic, broad-spectrum, second-generation fluoroquinolone antibiotic that shows activity against both gram-positive and gram-negative bacteria [1] through inhibition of their DNA gyrase. It is used to treat various bacterial infections, i.e. bone and joint infections, respiratory tract infections, skin infections, several infectious diarrheas, urinary tract infections, typhoid fever, gastrointestinal and sexually transmitted diseases [2-4]. Also, the United States Food and Drug Administration has approved it to prevent or slow down anthrax after exposure [5]. There are greater chances for $\mathrm{Cf}$ to enter the environment via urine and wastewater due to its incomplete metabolization in the body. It has high sorption affinity onto soils and its residues have been reported in rivers, groundwater and accumulated in soils. Due to its continuous input and persistence in the environment, it affects mammalian cell replication causing adverse drug reactions and thus threatens human health. Based on the above-mentioned facts, determination of $\mathrm{Cf}$ residues in biological fluids (urine, blood and tissues), soil and water has been receiving more attention nowadays $[4,6]$.

As per United States Pharmacopeia the reference method for the quantitative determination of ciprofloxacin in Pharmaceuticals is HPLC method [2, 7]. There are several analytical methods reported in literatures for the determination of $\mathrm{Cf}$ in its different forms and preparations. Some of these methods are spectrophotometric [8], fluorescence [4, 9], electrochemical [10], chemiluminescence [11], capillary electrophoresis [12], chromatographic [13], and flow injection analysis (FIA) methods [3, 14]. Although some of the reported methods mentioned above have pros and cons in terms of selectivity, sensitivity, time and cost of analysis and simplicity but analytical methods always have space for improvement and extension. The associated limitations with some methods include high cost and complexity of instrumentation, unavailability of skilled technical personals and instruments (as in case of HPLC and LCMS) and longer analysis time. In many cases several sample preparation and clean-up steps are involved and some of the methods are prone to negative interferences effects.

Semiconductor nanocrystals synthesized from elements of groups II and VI or groups III and V include CdSe, CdS, CdTe, and $\mathrm{ZnS}$ [15]. These are usually referred to as quantum dots (QDs), and have diameters in the range of 2-10 nm. These are excellent inorganic luminophores and due to the apparent quantum confinement effect, QDs have unique optical and electrical properties such as broad excitation spectra, high luminous efficiency, narrow and symmetrical emission spectrum, controllable emission wavelength, good water dispersibility and low photobleaching sensitivity equated with the equivalent bulk materials [16]. Many reports on the use of QDs with different surface modification are available in the literature for analysis of antibiotics and other medications [4], veterinary medicines [15], compounds found in human body [16-18], neurotransmitters and radioprotectants [16, 19], metal ions [20], anions [16, 21], toxicants [22], pesticides [16, 23], antioxidants [24], explosives [16], industrial chemicals [25] and many more.

All the scaffolds having QDs as the main skeleton and used for fluorescencesensing involve change in fluorescence intensity of QDs. The nanoflurophores especially, metal chalcogenides are doped with transition metals semiconductors in which the doped ions act as luminescence centers, intensify the luminescence and shorten the life time due to the interaction of the sp electron hole of the metal chalcogenide and the $3 \mathrm{~d}$ electrons of $\mathrm{Mn}^{2+}$ ion. These have excellent optical properties in comparison to their corresponding host nano-materials [15]. In the past decades, Cadmium QDs have been widely used for a variety of luminancebased purposes [26]. However, the toxic effects of cadmium QDs restricted their application in biological and environmental detection [27]. Fortunately, $\mathrm{ZnS}$ QDs having low toxicity, wide band gap energy $(3.7 \mathrm{eV})$ [17] for various dopants and small exciton Bohr radius is the perfect host material to replace $\mathrm{Cd}$ [28]. Mndoped $\mathrm{ZnS}$ QD causes the red-shift of the initial emission wavelength of $\mathrm{ZnS}$ quantum dots from $450 \mathrm{~nm}$ to $590 \mathrm{~nm}$ [29], where the redshift is triggered by the variation of transition from $4 \mathrm{~T} 1$ to $6 \mathrm{~A} 1$ in $\mathrm{ZnS}$ crystal stimulated by $\mathrm{Mn}$ ions [30].

In order to improve the selectivity, solubility in aqueous/biological system and stability of doped quantum dots compared to their corresponding bare ones and to diminish the QDs' crystal defect, surface ligands engineering is carried out [17]. Several capping agents including amino acids [31], cetyltrimethyl ammonium bromide, polyethylenimine, DNA sequence, thioglycolic acid, dpenicillamine, mercaptopropionic acid, N-(2-hydroxybenzyl)- cysteine, thioglycerol, peptide, etc. have been reported [17].

The aim of the present work was to develop a simple, sensitive and fast spectrofluorimetric method for determination of ciprofloxacin based on its quenching effect on the fluorescence intensity of colloidal water soluble TGA caped, Mn doped ZnS quantum dots (QDs). The QDs having characteristic fluorescence spectra were characterized using Energy Dispersive X-Ray and Xray Diffraction techniques. The effect of various parameters such as concentration of QDs, time, $\mathrm{pH}$, common excipient and metal ions on the quenching phenomenon was investigated. The method was validated using various statistical parameters and average \% recovery from commercial formulations was investigated. The method under optimized conditions was found to be interference free and was successfully applied to determine ciprofloxacin in spiked serum and urine samples. 


\section{EXPERIMENTAL}

\section{Chemicals and Reagents}

Analytical grade chemicals were used throughout the research work and no further purification was carried out. Required chemicals were zinc sulphate heptahydrate (Scharlau, Spain, EU), Manganese sulphate monohydrate, sodium sulphide monohydrate, thioglycolic acid, (TGA), and ethanol from Merck (Darmstadt Germany), phosphoric acid, acetic acid, boric acid, hydrochloric acid and sodium hydroxide (Sigma-Aldrich, St. Louis, USA). Standard reference of ciprofloxacin was thankfully received from Shaheen pharmaceutical Industry in Swat. Commercial formulations of ciprofloxacin such as ciproquine and ciprol were brought from local market.

\section{Instruments}

Spectroflourophotometer (RF5301 PC, Shimadzu, Japan) having 150-watt Xenon lamp as excitation source with $1.0 \mathrm{~cm}$ quartz cell was used throughout the experimental work for fluorescence measurements. The emission and excitation slit width was $4 \mathrm{~nm}$ for fluorimetric operation. Required chemicals were weighed using electrical digital balance Schimadzu ATY224 (Shimadzu Corp., Kyoto, Japan) and stirring of the reaction mixture was carried out with the help of heating magnetic stirrer (Model Hei-Tec P/N: 505-30000-00, Heidolph Germany). X-ray Diffraction (XRD) analysis of the QDs was done using X-ray diffractometer (Rigaku D/Max-II, Japan) with $\mathrm{Cu}-\mathrm{K} \alpha$ radiation $(40 \mathrm{kV}, 30 \mathrm{~mA})$. Energy Dispersive X-Ray (EDX) (JSM 5910, JEOL Japan) was employed for the elemental analysis of the QDs. Borosilicate glassware and apparatus were used for respective operation.

\section{Preparation of TGA capped Mn dopped ZnS QDs}

Colloidal water-soluble Mn doped ZnS QDs capped with TGA were synthesized by arrested precipitation method via the procedure described by Gonzalez [32] with little modification. In a glass beaker, $0.3 \mathrm{~mL}$ of TGA, $10 \mathrm{~mL}$ of $\mathrm{ZnSO}_{4} .7 \mathrm{H}_{2} \mathrm{O}(0.014 \mathrm{M})$ and $5.0 \mathrm{ml}$ of $\mathrm{MnSO}_{4} \cdot \mathrm{H}_{2} \mathrm{O}(0.0012 \mathrm{M})$ solutions were mixed and by drop wise addition of $\mathrm{NaOH}(1.0 \mathrm{M})$, with vigorous stirring, $\mathrm{pH}$ of the mixture was adjusted up to $8.0 \pm 0.5$. During addition of $\mathrm{NaOH}$ solution to the mixture of TGA and $\mathrm{Zn}^{2+}$, it was observed that the colour of the solution became yellow along with little whitish curds formation. The curds disappeared immediately and finally clear solution was obtained. This change was due to different dissociation levels of sulfihydryl and carboxylate groups at different $\mathrm{pH}$ levels, shaping $\mathrm{Zn}$ thio complexes with different structures. After the adjustment of $\mathrm{pH}, 10 \mathrm{~mL}$ of $\mathrm{Na}_{2} \mathrm{~S} .9 \mathrm{H}_{2} \mathrm{O}(0.014 \mathrm{M})$ was added drop wise with vigorous stirring. Mn dopped ZnS QDs capped with TGA obtained were separated in precipitate from by the addition of ethanol and then filtering the mixture. The residue was air dried and a portion of the QDs were subjected to characterization.

\section{Procedure for spectrofluorimetric determination of ciprofloxacin}

Required solutions of QDs were prepared which remained soluble and stable in distilled water at room temperature without any precipitation. In order to optimize the concentration of QDs and the $\mathrm{pH}$ of the medium for maximum fluorescence quenching and maximum sensitivity, different volumes of the stock solution $\left(100 \mu \mathrm{g} \mathrm{mL}^{-1}\right)$ of QDs were taken in a series of $10 \mathrm{~mL}$ volumetric flasks for achieving concentration in the range of $8-12 \mu \mathrm{g} \mathrm{mL}^{-1}$, added $2.0 \mathrm{~mL}$ of $20 \mu \mathrm{g}$ $\mathrm{mL}^{-1}$ of standard Cf solution to each flask and emission fluorescence intensity (FI) of the QDs (represented as $\mathrm{F}^{\circ}$ ) and that of $\mathrm{Cf}$ added QDs (represented as F) was measured at $632 \mathrm{~nm}$ after excitation at $315 \mathrm{~nm}$ against reagent blank using spectroflourimeter. The relative FI (represented as $\mathrm{F}^{\circ} / \mathrm{F}$ ) was calculated which shows the extent of fluorescence quenching.

Similarly, for investigation of the effect of $\mathrm{pH}$ on the quenching phenomenon, in a number of volumetric flasks $(10 \mathrm{~mL}), 1.0 \mathrm{~mL}$ of QDs solution $(100 \mu \mathrm{g} \mathrm{mL}$ $\left.{ }^{1}\right), 2.0 \mathrm{~mL}$ of Britton-Robinson buffer solution in the range of $\mathrm{pH} 2-10$ and 2.0 $\mathrm{mL}$ of standard ciprofloxacin solution were mixed and made the volume with distilled water up to the mark and fluorescence intensity in each case was measured as mentioned above.

In order to study the fluorescence quenching as a function of concentration of $\mathrm{Cf}$, in several volumetric flasks $(10 \mathrm{~mL}), 10 \mu \mathrm{g} \mathrm{mL}{ }^{-1}$ solutions of QDs and different volumes of $\mathrm{Cf}$ solution to achieve concentration in the range of 0.2-10 $\mu \mathrm{g} \mathrm{mL}^{-1}$ were mixed. To each flask, $2.0 \mathrm{~mL}$ of buffer of $\mathrm{pH} 8$ was added and each solution diluted up to the mark with distilled water. The blank solution of QDs was prepared without the addition of $\mathrm{Cf}$ and measured the fluorescence intensity.
Effect of excipients and common ions on quantification of $\mathrm{Cf}$ (Interference study)

Interference study was carried out by mixing $2.0 \mu \mathrm{g} \mathrm{mL}^{-1}$ ciprofloxacin, 2,4 and $6 \mu \mathrm{g} \mathrm{mL} L^{-1}$ solutions of common excipients in the ratio of 1:1, 1:2 and 1:3. Each solution was buffered using $2.0 \mathrm{~mL}$ of buffer of $\mathrm{pH} 8$ and distilled water was added for dilution upto the final volume of $10 \mathrm{~mL}$. The fluorescence measurements were done under the optimized conditions as a function of the excipient concentration and \% recoveries were calculated.

\section{Sample solution preparation}

Two tablets of each commercial brand (Ciprol $500 \mathrm{mg}$, Ceproquine $250 \mathrm{mg}$ ) were weighed and average mass of each tablet was found to be 1.787 and 0.890 $\mathrm{g}$ for ciprol and ciproquine respectively. Tablets were ground into fine powder, mixed and weighed, dissolved in ethanol $(20 \mathrm{~mL})$, with vigorous shaking, then filtered and transferred to volumetric flasks $(100 \mathrm{~mL})$ and diluted with distilled water. The proposed method was extended to quantify $\mathrm{Cf}$ in each commercial formulation of three different concentrations $\left(2.0,4.0\right.$ and $\left.6.0 \mu \mathrm{g} \mathrm{mL}^{-1}\right)$. The quantity of active ingredient of $\mathrm{Cf}$ was calculated using standard calibration curve and the respective linear equation.

In a number of volumetric flasks $(10 \mathrm{~mL})$, known amount of each commercial formulation (equivalent to $2.0 \mu \mathrm{g} \mathrm{mL}^{-1}$ ) and $2.0,4.0$ and $6.0 \mu \mathrm{g} \mathrm{mL}^{-1}$ of standard sample were mixed in triplicates that formed final concentration as 4.0, 6.0 and $8.0 \mu \mathrm{g} \mathrm{mL}^{-1}$ of Cf with $2.0 \mathrm{~mL}$ of $10 \mu \mathrm{g} \mathrm{mL}^{-1}$ of QDs and $2.0 \mathrm{~mL}$ of buffer of $\mathrm{pH}$ 8 and dilution was done with distilled water. For quantification purposes, the successive steps of the proposed method were followed, concentration of the drug was determined and $\%$ recoveries calculated.

Urine and blood serum samples were provided by a local pathology laboratory collected from a healthy male volunteer following all ethical guidelines and stored frozen until analyzed. During analysis, triplicates of $1.0 \mathrm{~mL}$ of serum sample was spiked with variable concentration of Cf $\left(2.0-6.0 \mu \mathrm{g} \mathrm{mL}^{-1}\right)$, then acetonitrile $(1.2 \mathrm{~mL})$ was added to remove serum protein. Subsequently, for removal of the serum protein residues, the mixture was centrifuged for $15 \mathrm{~min}$ at $3500 \mathrm{rpm}$ and the supernatant was transferred to a $10 \mathrm{~mL}$ volumetric flask in each case. Then FI was measured using the procedure outlined above and recovery in each case was calculated.

Urine samples $(4.0 \mathrm{~mL}$ each) were spiked with different concentration of $\mathrm{Cf}$ (2.0-6.0 $\left.\mu \mathrm{g} \mathrm{mL}^{-1}\right)$ in triplicates. To each mixture $2.0 \mathrm{~mL}$ of $10 \mu \mathrm{g} \mathrm{mL}^{-1}$ of QDs and $2.0 \mathrm{~mL}$ of buffer of $\mathrm{pH} 8$ were added and final dilution was done with distilled water. For each solution FI was measured and concentration and the subsequent $\%$ recovery of $\mathrm{Cf}$ was calculated.

\section{RESULTS AND DISCUSSION}

The fluorescent spectra of TGA capped Mn doped ZnS QDs was recorded by scanning the $\lambda_{\mathrm{ex}}$ and $\lambda_{\mathrm{em}}$ in the range of 250-750 $\mathrm{nm}$ and it was observed that QDs show excitation peak at $315 \mathrm{~nm}$ followed by emission peak at $632 \mathrm{~nm}$. The broad band emission at longer wavelength $(632 \mathrm{~nm})$ was due to trap state emission between the valance and conduction band that originates from surface of QDs.

\section{Mechanistic approach to quantification of Cf using TGA capped Mn-ZnS} QDs

Nowadays, the application of QDs for the sensory system based on quenching of the FI of QDs has got extensive attention because of electron transfer (ET), fluorescence resonance energy transfer, or other interactions that occur at the surface of QDs. Recently, it has been reported in various studies that electron transfer occurs when hole or electron acceptor specie get attached at the QDs surface and thus affect the recombination of electron-hole pair and decreases the fluorescent intensity [33]. The above facts justify the capability of $\mathrm{Cf}$ to get adsorbed onto the surface of Mn-ZnS QDs capped by TGA, thus affecting radiative recombination mechanism which reduces the fluorescence intensity.

\section{Characterization of QDs}

Energy Dispersive X-Ray (EDX) analysis is an important tool for elemental analysis and for detection of impurity. Figures $1 \mathrm{a}$ and $1 \mathrm{~b}$ shows the EDX spectra of Mn doped $\mathrm{ZnS}$ and TGA capped $\mathrm{Mn}$ doped $\mathrm{ZnS}$ respectively. Figure 1a shows peak for $\mathrm{Mn}, \mathrm{Zn}$ and $\mathrm{S}$ confirming the formation of $\mathrm{Mn}$ doped $\mathrm{ZnS}$. Figure $1 \mathrm{~b}$ 
shows the peaks for $\mathrm{C}, \mathrm{O}, \mathrm{Mn}, \mathrm{Zn}$ and $\mathrm{S}$, which confirm the synthesis of TGA capped $\mathrm{Mn}$ doped $\mathrm{ZnS}$. All the peaks were related with the constituent elements, verifying no impurities are present.

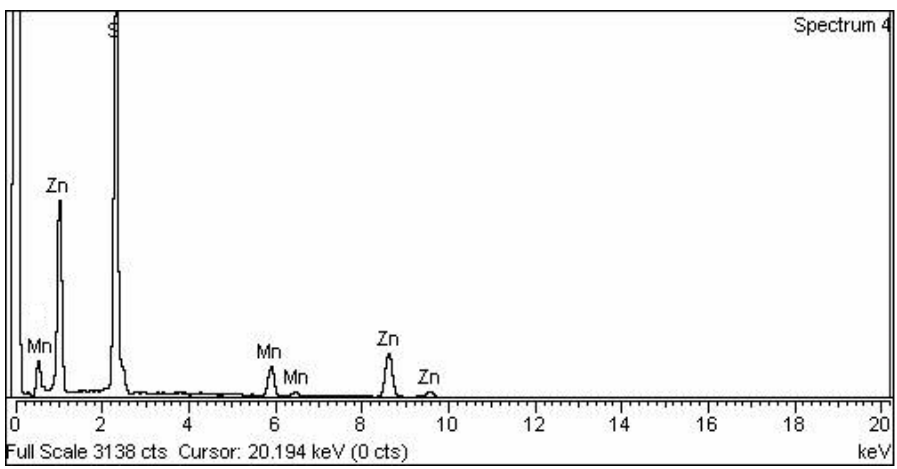

Figure 1a. EDX spectra of Mn doped ZnS QDs.

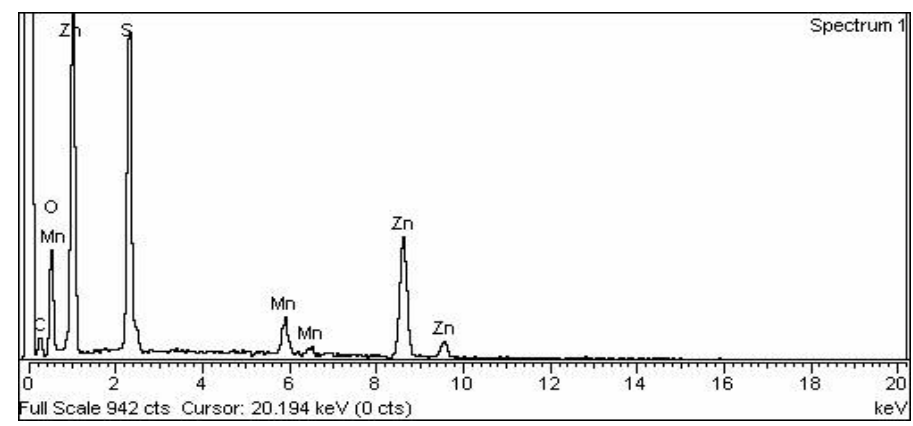

Figure 1b. EDX spectra of TGA-capped Mn doped ZnS QDs.

Figures $2 \mathrm{a}$ and $\mathrm{b}$ show the X-ray Diffraction (XRD) pattern of TGA capped $\mathrm{Mn}-\mathrm{ZnS}$ and Mn-ZnS respectively. The XRD spectrum shows that the peaks appeared at $28.6^{\circ}, 48^{\circ}$ and $55.4^{\circ}$ indicates the crystal plane of (111), (220) and (311) respectively, which suggests the nanocrystals cubic closed packed structure of Zinc blend. The findings are in good agreement with those reported in the literature [JCPDS NO: 5-0566] [34]. From the width of the XRD peak the average grain size was estimated to be $6 \mathrm{~nm}$ using the Scherrer equation. Since the particle size is greater than excitonic Bohr radius of $\mathrm{ZnS}(2.5 \mathrm{~nm})$, the particles are confined to a weak quantum regime [35].
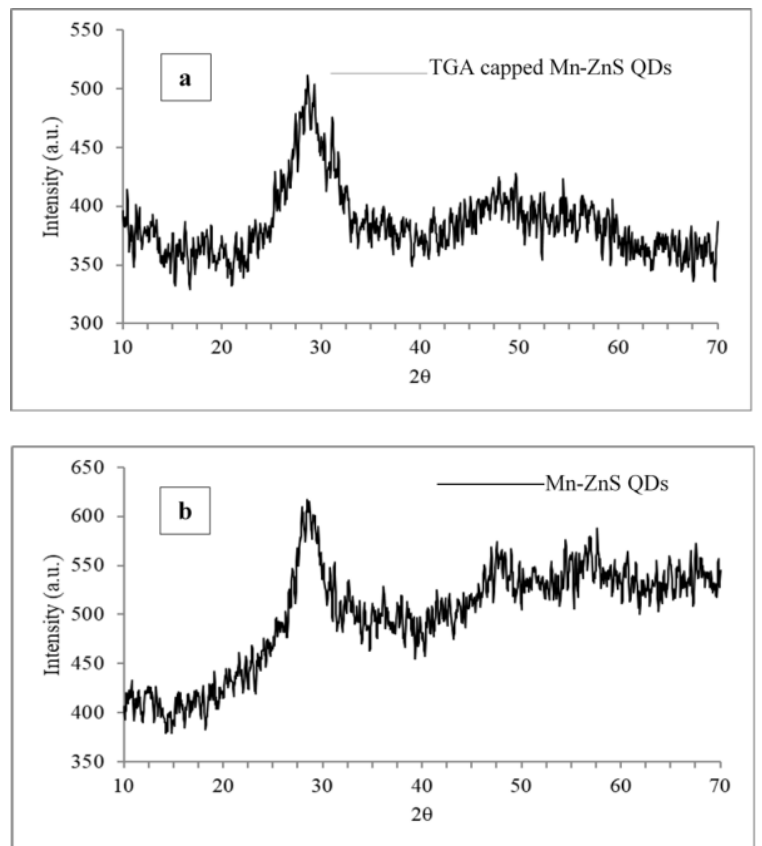

Figure 2. XRD pattern of (a) TGA capped Mn-ZnS QDs and (b) Mn-ZnS QDs.
Optimization of the conditions for maximum fluorescence Quenching of QDs

The concentration of QDs was varied in the range of 8-14 $\mu \mathrm{g} \mathrm{mL}^{-1}$ at a fixed concentration of $\mathrm{Cf}\left(4.0 \mu \mathrm{g} \mathrm{mL}^{-1}\right)$ and as shown in figure 3, it was found that maximum quenching occurs with $10 \mu \mathrm{g} \mathrm{mL}^{-1}$ of QDs. This concentration of QDs was selected optimum and was kept constant during further studies.

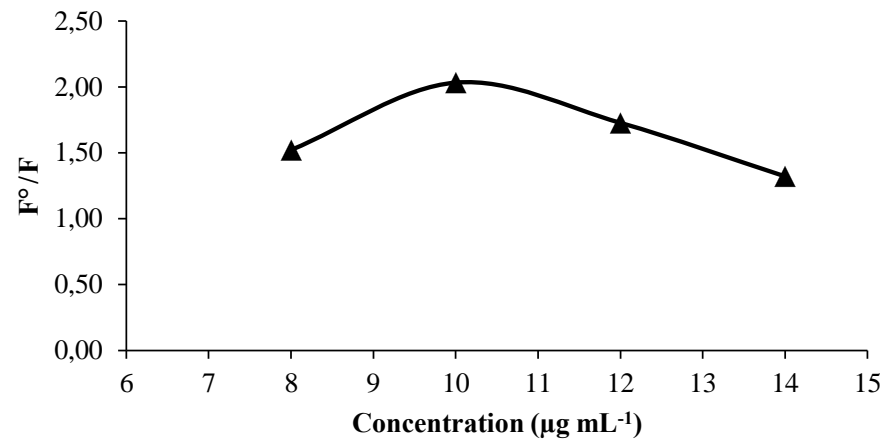

Figure 3. Quenching effect as a function of concentration of QDs.

The effect of $\mathrm{pH}$ on quenching was studied by using Briton Robinson buffer in the range of $\mathrm{pH} 2-10$ and maximum quenching was observed at $\mathrm{pH}$ 8. This observation can be attributed to the fact that at lower $\mathrm{pH}$, the TGA would get detached from the QDs surface and form thiol by protonation which decreases the fluorescence intensity. The results are shown in figure 4.

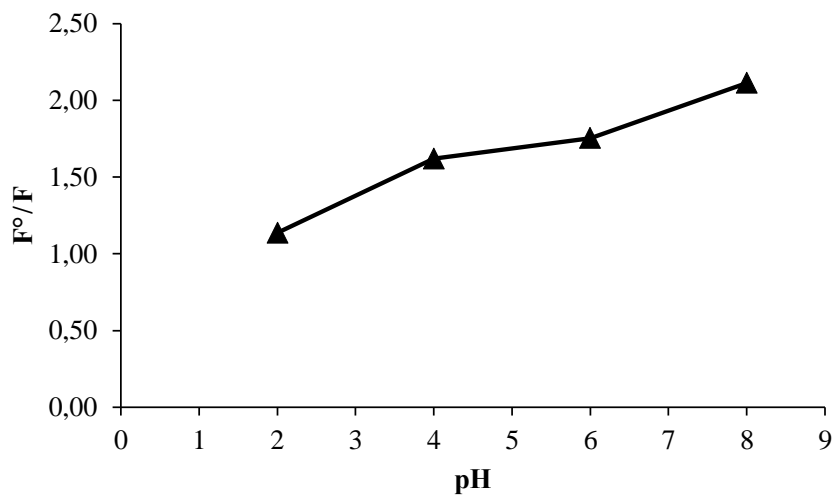

Figure 4. Effect of $\mathrm{pH}$ on extent of quenching of QDs by Cf.

\section{Effect of concentration of $\mathrm{Cf}$ on extent of quenching of FI of QDs}

The relative FI of QDs was investigated as a function of concentration of $\mathrm{Cf}$ in the range of $\left(0.5-10 \mu \mathrm{g} \mathrm{mL}^{-1}\right)$ at $\mathrm{pH} 8$ and it was found to increase linearly with excellent correlation coefficient $\left(r^{2}=0.993\right)$. The results are shown in figure 5 . The curve and the linear equation shown in figure 5 was used for calculation of concentration of $\mathrm{Cf}$ in subsequent studies.

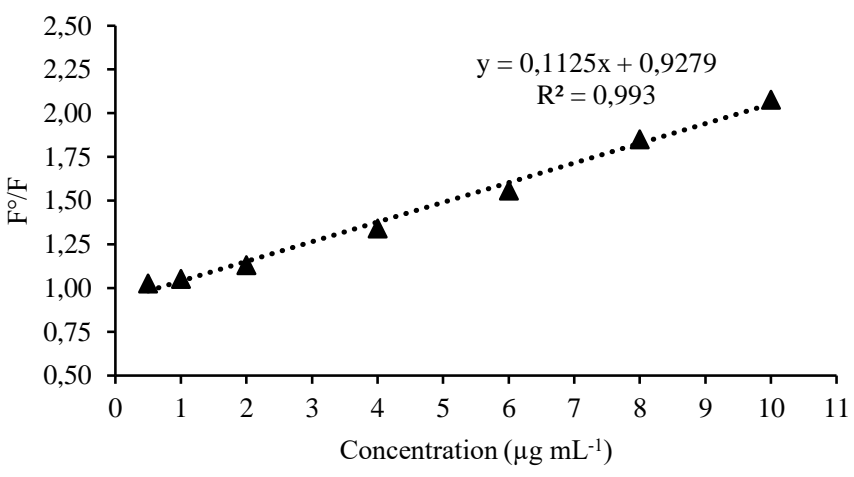

Figure 5. Effect of concentration of $\mathrm{Cf}$ on extent of quenching of FI of QDs. 


\section{Effect of common excipients and interference metal ions}

Excipients which are normally used in the manufacturing of $\mathrm{Cf}$ tablets include sorbitol, glucose, lactose, sucrose, magnesium stearate and starch. These can possibly interfere with the determination following the proposed method and thus the selectivity of the method become doubtful. Likewise, metal and compound ions such as $\mathrm{Na}^{+}, \mathrm{K}^{+}, \mathrm{Ca}^{2+}, \mathrm{Mg}^{2+}, \mathrm{NH}_{4}{ }^{+}, \mathrm{HCO}^{3-}$ and $\mathrm{CO}_{3}^{2-}$ may also interfere in the analysis. These possible interfering substances were then added sequentially to assay the samples at concentrations 1-3-fold higher than the concentration of Cf $\left(2.0 \mu \mathrm{g} \mathrm{mL}^{-1}\right)$. The results are given in figure 6 , which show that the method is interference free in both cases i.e. in case of common excipients as well as in case of common ions.

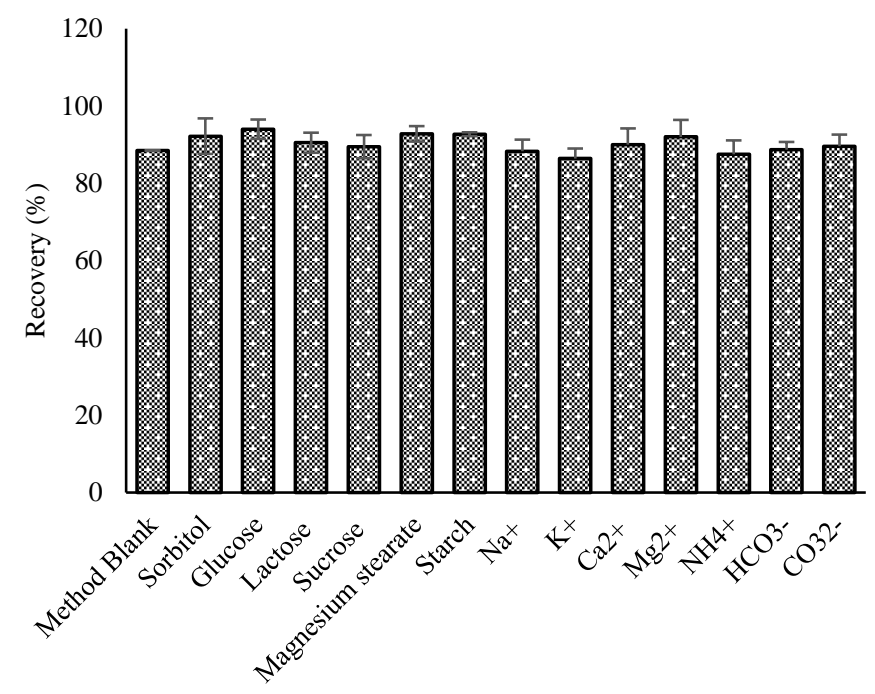

Excipient, Ion

Figure 6. Effect of excipients and common ions on the \% recovery of Cf.

Application of the proposed method for quantification of $\mathrm{Cf}$ in drug formulations and biological samples

To prove its utility, the proposed method was applied to measure the concentrations of $\mathrm{Cf}$ in serum and urine samples and also in commercial formulations at different spiking levels. Percent recovery of $\mathrm{Cf}$ from two different formulations i.e. ciprol $500 \mathrm{mg}$ and ciproquine $250 \mathrm{mg}$ was investigated. The quantity of active ingredient was calculated using standard calibration curve. The results as given in table 1, indicate excellent average percent recovery $( \pm \mathrm{SD})$ in the range of $92.2 \pm 1.8$ to $99.5 \pm 1.5 \mu \mathrm{g} \mathrm{mL}^{-1}$.

Table 1. Recovery studies for $\mathrm{Cf}$ formulations in the form of tablets.

\begin{tabular}{|l|c|c|c|c|}
\hline \multirow{2}{*}{$\begin{array}{l}\text { Drug } \\
\text { Formulation }\end{array}$} & \multicolumn{2}{|c|}{ Amount of active ingredient of $\mathbf{C f}\left(\boldsymbol{\mu g} \mathbf{~ m L}^{-\mathbf{1}}\right)$} & \multirow{2}{*}{$\begin{array}{c}\text { Average \% } \\
\text { Recovery } \pm \text { SD }\end{array}$} \\
\cline { 2 - 5 } & $\begin{array}{c}\text { Contained in } \\
\text { drug solution }\end{array}$ & Added & found & \\
\hline \multirow{3}{*}{$\begin{array}{l}\text { Ciprol } \\
500 \mathrm{mg}\end{array}$} & & 2 & 3.77 & $94.2 \pm 3.0$ \\
\cline { 3 - 5 } & \multirow{2}{*}{2} & 4 & 5.82 & $97.0 \pm 2.7$ \\
\cline { 3 - 5 } & & 6 & 7.38 & $92.2 \pm 1.8$ \\
\hline \multirow{2}{*}{$\begin{array}{l}\text { Ciproquine } \\
250 \mathrm{mg}\end{array}$} & & 2 & 3.98 & $99.5 \pm 1.5$ \\
\cline { 3 - 5 } & & 4 & 5.86 & $97.6 \pm 1.4$ \\
\cline { 3 - 5 } & & 6 & 7.66 & $95.7 \pm 1.2$ \\
\hline
\end{tabular}

The proposed method was also applied to determine average percent recovery $( \pm$ SD) of $\mathrm{Cf}$ from spiked human serum and urine samples. The developed method shows good applicability in term of higher percent recoveries $(90.5 \pm 1.2$ to $96.7 \pm 1.4 \mu \mathrm{g} \mathrm{mL}^{-1}$ for blood serum and $94.0 \pm 1.2$ to $98.5 \pm 1.4 \mu \mathrm{g} \mathrm{mL}^{-1}$ for urine samples) as shown by the results given in table 2 .
Table 2. Extraction recovery for $\mathrm{Cf}$ from spiked serum and urine samples.

\begin{tabular}{|c|c|c|c|c|}
\hline \multirow{3}{*}{ Sample } & \multirow{2}{*}{$\begin{array}{c}\text { Number of } \\
\text { replicates }\end{array}$} & \multicolumn{2}{|c|}{$\begin{array}{c}\text { Amount of active ingredient of Cf } \\
\left(\boldsymbol{\mu g} \mathbf{~ m L}^{-1}\right)\end{array}$} & $\begin{array}{c}\text { Average \% } \\
\text { Recovery } \pm \text { SD }\end{array}$ \\
\cline { 2 - 5 } & & Added & found & \\
\hline \multirow{3}{*}{ Serum } & 3 & 2 & 1.81 & $90.5 \pm 1.2$ \\
\cline { 2 - 5 } & 3 & 4 & 3.87 & $96.7 \pm 1.4$ \\
\cline { 2 - 5 } & 3 & 6 & 5.48 & $91.3 \pm 1.4$ \\
\hline \multirow{3}{*}{ Urine } & 3 & 2 & 1.97 & $98.5 \pm 1.4$ \\
\cline { 2 - 5 } & 3 & 4 & 3.76 & $94.0 \pm 1.2$ \\
\cline { 2 - 5 } & 3 & 6 & 5.74 & $95.6 \pm 0.5$ \\
\hline
\end{tabular}

\section{Analytical and statistical parameters}

By employing the proposed method for determination of $\mathrm{Cf}$ under optimum conditions, replicate analysis of the lowest detectable concentration of $\mathrm{Cf}(0.5 \mu \mathrm{g}$ $\mathrm{mL}^{-1}$ ) and linearity studies were performed and analytical parameters for validation of the method were calculated as given in table 3. Over a concentrations range of $0.50-10 \mu \mathrm{g} \mathrm{mL}^{-1}$, the calibration curve for $\mathrm{Cf}$ showed an excellent linearity with the equation $y=0.1125 x+0.9279$ and $\mathrm{r}^{2}=0.993$. The standard deviation of the proposed method calculated against method blank was found to be $0.0056 \mu \mathrm{g} \mathrm{mL}^{-1}$

The limit of detection (LOD) and the limit of quantitation (LOQ) for Cf (signal to noise ratio 3:1 for LOD and 10:1 for LOQ) were calculated to be 0.15 and 0.50 $\mu \mathrm{g} \mathrm{mL} L^{-1}$ respectively. The average percentage recovery of $\mathrm{Cf}$ at varied spiking level $\left(2,4\right.$ and $\left.6 \mu \mathrm{g} \mathrm{mL}^{-1}, n=3\right)$ shows the accuracy of the proposed method and was found to be in the range of $92.2 \pm 1.8$ to $99.5 \pm 1.5 \mu \mathrm{g} \mathrm{mL}^{-1}$ for commercial formulations, $90.5 \pm 1.2$ to $96.7 \pm 1.4 \mu \mathrm{g} \mathrm{mL}^{-1}$ for serum and $94.0 \pm 1.2$ to $98.5 \pm 1.4$ $\mu \mathrm{g} \mathrm{mL}^{-1}$ for urine samples.

Table 3. Analytical and statistical parameters for the proposed method.

\begin{tabular}{|l|c|}
\hline \multicolumn{1}{|c|}{ Parameter } & Value \\
\hline$\lambda \mathrm{ex}(\mathrm{nm})$ & 315 \\
\hline$\lambda \mathrm{em}(\mathrm{nm})$ & 632 \\
\hline Linear range $\left(\mu \mathrm{g} \mathrm{mL}^{-1}\right)$ & $0.50-10$ \\
\hline Linear Equation & $\mathrm{y}=0.1125 \mathrm{x}+0.9279$ \\
\hline Correlation coefficient $\left(\mathrm{r}^{2}\right)$ & 0.993 \\
\hline Standard deviation $\left(\mu \mathrm{g} \mathrm{\textrm {mL } ^ { - 1 } )}\right.$ & 0.0056 \\
\hline Relative standard deviation $(\%)$ & 1.10 \\
\hline Limit of detection $\left(\mu \mathrm{g} \mathrm{mL}^{-1}\right)$ & 0.15 \\
\hline Limit of quantitation $\left(\mu \mathrm{g} \mathrm{mL} \mathrm{m}^{-1}\right)$ & 0.50 \\
\hline
\end{tabular}

\section{Comparison of the proposed method with reported analytical methods}

The proposed method was compared with previously published methods for quantification of ciprofloxacin (Table 4). The linearity of the proposed method is better than spectrophotometric methods and comparable to other fluorimetric methods. The proposed method is less precise and accurate as compared to a reported method [1] which involve the use of CdS QDs but the environment friendly nature of ZnS QDs as compared to CdS QDs outweigh this deficiency. 
Table 4. Comparison of Cf determination by several analytical methods.

\begin{tabular}{|c|c|c|c|c|c|}
\hline Method & Linearity range $\left(\mu \mathrm{g} \mathrm{mL}^{-1}\right)$ & $\operatorname{RSD}(\%)$ & $\underset{\left(\mu \mathrm{g} \mathbf{m L}^{-1}\right)}{\text { LOD }}$ & $\begin{array}{c}\text { LOQ } \\
\left(\mu \mathrm{g} \mathrm{mL} \mathbf{L}^{-1}\right)\end{array}$ & Ref. \\
\hline Present work & $0.5-10$ & 1.10 & 0.15 & 0.50 & - \\
\hline MPA-CdS QDs/Fluorescence probe & $0.13-150$ & 2.90 & 0.04 & - & [5] \\
\hline Fluorimetry & $0.4-100$ & 4.00 & 0.76 & - & {$[36]$} \\
\hline HPLC & $0.06-1.5$ & - & 0.02 & - & {$[37]$} \\
\hline HPLC-UV & $0.05-6.0$ & 1.80 & 0.15 & 0.05 & {$[38]$} \\
\hline ITP-CZE & 0.1-0.15 & 0.60 & 0.05 & 0.10 & {$[39]$} \\
\hline Square-wave stripping voltammetry & $0.01-0.75$ & 6.96 & 0.01 & 0.08 & [5] \\
\hline Differential pulse adsorptive voltammetry & $0.03-6.6$ & - & 16.00 & - & {$[40]$} \\
\hline Amperometry & $13.0-331$ & - & 1.98 & - & {$[41]$} \\
\hline Cyclic voltammetry & $0.033-331$ & - & 0.01 & 0.08 & {$[42]$} \\
\hline Potentiometry/MIP & $16.4-331$ & - & 3.30 & 16.50 & {$[43]$} \\
\hline Potentiometry/MIP & & - & 3.30 & - & {$[44]$} \\
\hline Potentiometry/Nano-composite based electro sensor & $0.3-3310$ & - & 0.30 & - & {$[45]$} \\
\hline Spectrophotometric & $1.0-15.0$ & 0.79 & 0.17 & 0.52 & {$[11]$} \\
\hline Charge transfer/Spectrophotometric & $7.5-42.3$ & 1.00 & - & - & {$[46]$} \\
\hline Reverse FIA Spectrophotometry & $0.5-16$ & $\leq 1.73$ & 0.20 & 0.69 & [3] \\
\hline SPE/Spectrophotometric & $0.05-0.3$ & 1.11 & 0.04 & 0.12 & [47] \\
\hline
\end{tabular}

ITP-CZE: Capillary isotachophoresis-capillary zone electrophoresis.

MIP: Molecularly imprinted polymers.

\section{CONCLUSIONS}

The present study describes development and validation of a simple and fast spectrofluorimetric method for determination of ciprofloxacin and is based on fluorescence quenching of the water soluble TGA capped Mn-ZnS QDs by the subject analyte. The QDs having characteristic fluorescence spectra with maximum excitation at $315 \mathrm{~nm}$ followed by an emission peak at $632 \mathrm{~nm}$ were prepared by arrested precipitation method and characterized by EDX and XRD. The effect of various factors such as $\mathrm{pH}$, time and concentration of QDs on the quenching of QDs by $\mathrm{Cf}$ was investigated. It was found that maximum quenching occurs at $10 \mathrm{ppm}$ of QDs at $\mathrm{pH}$ 8. The Stern-Volmer calibration plot was found to be linear in the range of $0.5-10 \mu \mathrm{g} \mathrm{mL}^{-1}$ with $\mathrm{r}^{2}=0.993$. The percent relative standard deviation, LOD and LOQ of the proposed method were found to be $1.10 \%, 0.15$ and $0.50 \mu \mathrm{g} \mathrm{mL}^{-1}$ respectively. High \% recovery $(90.5 \pm 1.2 \%$ to $98.5 \pm 1.4 \%$ ) was obtained for $\mathrm{Cf}$ in commercial formulations and biological samples. The method was found to be free of interferences when applied in the presence of common excipients like sorbitol, starch and glucose. The starting materials that were used for QDs preparation are easily available in the laboratory. In terms of accuracy and precision, the proposed method is comparable to many of the reported methods. The data evidently proves the potential of the proposed sensor QDs in biological analysis.

\section{REFERENCES}

1. R. Kharat, S. Jadhav, S. Pawar, A. Tamboli, PharmaTutor 3, 51 (2015).

2. N.S. Turkie, H.Q. Munshid, J. Pharm. Sci Res. 11, 1563 (2019).

3. S. Palamy, W. Ruengsitagoon, Spectrochim. Acta A. 190, 129 (2018).

4. T. Madrakian, S. Maleki, A. Afkhami, Sensor. Actuat. B-Chem. 243, 14 (2017).

5. xxA.-N. Kawde, M.A. Aziz, N. Odewunmi, N. Hassan, A. AlSharaa, Arab. J. Sci. Eng. 39, 131 (2014).

6. J. Wang, J. Dai, M. Meng, Z. Song, J. Pan, Y. Yan, C. Li, J. App. Polym. Sci. 131, (2014).

7. xxUSP38NF33, US. Pharmacopeia \& National Formulary, 2016, 3162-3270.
8. A.El-Kosasy, O. Abdel-Aziz, N. Magdy, N. El Zahar, Spectrochim. Acta A 157, 26 (2016)

9. M.E. El-Kommos, G.A. Saleh, S.M. El-Gizawi, M.A. Abou-Elwafa, Talanta 60, 1033 (2003).

10. M.P. Deepak, G.P. Mamatha, Anal. Bioanal. Electrochem. 7(5), 523 (2015).

11. Y.-D. Liang, J.-F. Song, X.-F. Yang, Anal. Chim. Acta 510, 21 (2004).

12. X. Xu, L. Liu, Z. Jia, Y. Shu, Food Chem. 176, 219 (2015).

13. S.N. Razzaq, M. Ashfaq, I. Mariam, I.U. Khan, S.S. Razzaq, G. Mustafa, J. Chilean Chem. Soc. 62, 3572 (2017).

14. I.M. Shakir, R.F. Hassan, Iraqi J. Sci. 57, 522 (2016).

15. S. Sadeghi, M. Jahani, F. Belador, Spectrochim. Acta A 159, 83 (2016).

16. H. Wang, C. Chen, Y. Liu, Y. Wu, Y. Yuan, Q. Zhou, Talanta 198, 242 (2019).

17. K. Abha, J. Nebu, J.A. Devi, R. Aparna, R. Anjana, A. Aswathy, S. George, Sensor. Actuat. B-Chem. 282, 300 (2019).

18. S. Kulchat, W. Boonta, A. Todee, P. Sianglam, W. Ngeontae, Spectrochim Acta A 196, 7 (2018).

19. Z. Wang, Y. Zhang, B. Zhang, X. Lu, Talanta 190, 1 (2018).

20. M. Hua, S. Yang, J. Ma, W. He, L. Kuang, D. Hua, Talanta 190, 278 (2018).

21. B.-H. Zhang, F.-Y. Wu, Y.-M. Wu, X.-S. Zhan, J. Fluoresc. 20, 243 (2010).

22. H. Bhardwaj, C. Singh, M. kumar Pandey, G. Sumana, Sensor. Actuat. BChem. 231, 624 (2016).

23. R. Ban, J.-j. Zhu, J. Zhang, Microchim. Acta 181, 1591 (2014).

24. X. Tan, S. Liu, Y. Shen, Y. He, J. Yang, Spectrochim. Acta A 133, 66 (2014).

25. Y. Gong, H. Wu, Z. Fan, Anal. Lett. 46, 2454 (2013).

26. W.C. Chan, S. Nie, Science 281, 2016 (1998).

27. N. Pradhan, D. Goorskey, J. Thessing, X. Peng, J. Am. Chem. Soc. 127, 17586 (2005).

28. H. Labiadh, B. Sellami, A. Khazri, W. Saidani, S. Khemais, Optic. Mater. 64 179 (2017).

29. J. Suyver, S. Wuister, J. Kelly, A. Meijerink, Nano Lett. 1, 429 (2001).

30. A. Bol, A. Meijerink, Phy. Rev. B 58, R15997 (1998).

31. P. Wu, X.-P. Yan, Chem. Soc. Rev. 42, 5489 (2013).

32. E. Sotelo-Gonzalez, M.T. Fernandez-Argüelles, J.M. Costa-Fernandez, A. Sanz-Medel, Anal. Chim. Acta 712, 120 (2012). 
33. M. Cao, M. Liu, C. Cao, Y. Xia, L. Bao, Y. Jin, S. Yang, C. Zhu, Spectrochim. Acta A 75, 1043 (2010).

34. N. S. Nirmala Jothi, G. J. Amish, R. J. Vijay, Mater. Chem. Phy. 138, 186 (2013).

35. Y. Motlan, G. Zhu, K. D. Tomsia, K. McBean, M. R. Phillips, E. M. Goldys, Optic. Mater. 29, 1579 (2007).

36. S. Shtykov, T. Smirnova, Y.G. Bylinkin, N. Kalashnikova, D. Zhemerichkin, J. Anal. Chem. 62, 136 (2007).

37. W. Gau, H. Ploschke, K. Schmidt, B. Weber, J. liquid Chromatogr. 8, 485 (1985).

38. M.T. Maya, N.J. Gonçalves, N.B. Silva, J.A. Morais, J. Chromatogr. B 755 , 305 (2001).

39. M. Hernández, C. Aguilar, F. Borrull, M. Calull, J. Chromatogr. B 772, 163 (2002).
40. H. Yi, C. Li, Russian J. Electrochem. 43, 1377 (2007).

41. L. Fotouhi, M. Alahyari, Colloid. Surf. B 81, 110 (2010).

42. A.A. Ensafi, A.R. Allafchian, R. Mohammadzadeh, Anal. Sci. 28, 705 (2012).

43. A.H. Kamel, W.H. Mahmoud, M.S. Mostafa, Anal. Meth. 3, 957 (2011).

44. H.M. Oliveira, F.T. Moreira, M.G.F. Sales, Electrochim. Acta 56, 2017 (2011).

45. F. Faridbod, T. Poursaberi, P. Norouzi, M.R. Ganjali, Int. J. Electrochem. Sci. 7, 3693 (2012).

46. S. Mostafa, M. El-Sadek, E.A. Alla, J. Pharmacol. Biomed. Anal. 27, 133 (2002).

47. M.I. Pascual-Reguera, G.P. Parras, A.M. Díaz, Microchem. J. 77, 79 (2004). 